\title{
Cristóbal de Aguilar Casaverde, retratista limeño del siglo XVIII
}

Ricardo Estabridis Cárdenas

En el panorama de la pintura del siglo XVIII, en el Reino del Perú, se definen claramente las diferencias entre la pintura realizada en los dos más importantes centros de producción, Lima y Cuzco. Mientras en Cuzco como es sabido se va camino hacia un arte que desde el punto de vista formal opta por el carácter estereotipado de sus figuras y una pintura casi bidimensional y decorativista, en Lima se rige más por lo académico, entendido como un mayor respeto por las proporciones, perspectiva y composición en general.

En la Ciudad de los Reyes en lo que respecta a la temática, si bien no se deja de lado la pintura religiosa, gana terreno entre los comitentes los gustos de los burgueses y nobles criollos por la pintura profana, tal como dan cuenta los inventarios de la época, donde se citan obras de temática mitológica, bodegones, paisajes y escenas de género'; además, será en esta centuria cuando el arte del retrato alcanza su máximo apogeo, ya que en el contexto de la época ellos se convierten en símbolos representativos del poder, no sólo del consabido cargo de virrey, sino principalmente de la burguesía y nobleza americana que adquiere desde mediados del siglo una autoseguridad, producto no sólo de sus arcas, sino también de las nuevas corrientes del pensamiento ilustrado ${ }^{2}$.

A pesar de las diferencias entre las escuelas limeña y cuzqueña, en la primera mitad del siglo XVIII, la difusión de la cuzqueña es tal que al parecer inunda el mercado capitalino e influye en artistas de la talla de Cristóbal Lozano, como ya se ha demostrado ${ }^{3}$. Sin embargo, Lozano pronto se desprende de ella y pone en evidencia un gusto arcaizante por la pintura barroca española de la segunda mitad del siglo anterior y toma como modelo a Ribera, pero sobre todo a Murillo, indudablemente influenciado por la existencia de obras de estos pintores en colecciones locales como

Escribano: Orencio de Ascurrunz. Protoc. 83, 1765, Fol. 476. AGN. Memoria de los bienes de Pedro José Bravo de Lagunas y Castilla.

Estabridis, Ricardo: "El retrato del siglo XVIII en Lima como símbolo de poder". En El Barroco Peruano 2. Edit.Banco de Crédito del Perú. Lima, 2003, p.135.

Estabridis, Ricardo: "Cristóbal Lozano en el Monasterio del Carmen". En Diario El Comercio, Lima, 8 de marzo de 1994, C 7. Ver también Estabridis, R:"El retrato en Lima en el siglo XVIII: Las pinturas de Cristóbal Lozano". En Tradición, estilo o escuela en la pintura iberoamericana. Siglos XVI-XVIII. México, 2004, p. 105. Este estudio se presentó como ponencia en el Primer Seminario de Pintura Virreinal Iberoamericana efectuado en Lima con el patrocinio del Banco de Crédito del Perú en septiembre del año 2000. 
la de Pedro José Bravo de Lagunas y Castilla, en cuya memoria de 1759 se hace alusión a una pintura de La Asunción de este artista, copia de Murillo. Asimismo, se ha demostrado la persistencia del uso de los grabados flamencos en sus obras ${ }^{4}$.

Hemos calificado a Lozano (1705-1776), creemos que con justa razón, como paradigma de la pintura limeña del siglo XVIII, ya que en él se dan todos los caracteres de la escuela en la centuria dieciochesca, y están documentados de su pincel, todos los tipos de género que se practicaron en la época. En Lima alcanzó gran fama y fue tomado como modelo por varios pintores, e incluso trascendió fronteras al ser enviadas sus pinturas a la corte de Madrid. Cuando se habla de él en documentos oficiales del siglo XIX, en las primeras décadas de la república, se consignan sus obras entre las prohibidas de exportar al extranjero por ser patrimonio nacional. En el Decreto Supremo 556 de fecha 1 de marzo de 1841, en el artículo 20 se lee:

"Queda prohibida la extracción al extranjero de las pinturas antiguas originales, ya sea en lienzo, tabla o lámina de metal, de los maestros de la escuela italiana y española, como también los originales o copias del célebre Lozano, pintor del paí" $"$."

Su más cercano seguidor, y para algunos estudiosos rival, pero circunscrito hasta el momento, en base a lo que se tiene documentado de su pincel, al género del retrato, fue Cristóbal de Aguilar.

Motiva el presente ensayo el pintor Cristóbal de Aguilar Casaverde, con el deseo de ordenar la cronología de sus obras conocidas, que van de 1745 a 1769 , incluir algunas nuevas firmadas y atribuidas y sobre toda dar a la luz su testamento cuya trascripción incluimos al final de este escrito.

Del testamento fechado el 22 de diciembre de 1769, ante el escribano de su Majestad Andrés de Sandoval, teniendo por testigos a don Tomás Sánchez, Estanislao del Castillo, al licenciado Juan Cosio, al Presbítero Bernardo de Avila y a don Antonio de Eguren, se desprende que era natural de Lima, hijo legítimo de don Francisco de Aguilar y de doña Josefa Casaverde ya difuntos, lastimosamente sin indicar fecha de nacimiento. Asimismo, que fue casado con doña Silvestra Morales, igualmente ya difunta, con quien tuvo cuatro hijos, Mariano Aguilar, fraile de la orden de Predicadores, Bárbara, Rudesindo y Tomás de Aguilar. Nombra en él como albacea y tenedor de sus bienes a su hermano don Lucas de Aguilar. Algo importante del escrito es que se declara pintor y que tiene algunas obras en proceso ${ }^{6}$.

En cuanto a su situación económica, en el momento de hacer el testamento dice: "como pobre que soy". Llama la atención que se declare pobre ya que en el mismo año de 1769 firma y fecha tres retratos importantes, uno del virrey Amat y dos de los marqueses de Santiago. Es indudable que a pesar de que Aguilar pintó varios retratos de virreyes, de catedráticos de San Marcos, de la nobleza y de religiosos destacados, e

\footnotetext{
Estabridis, Ricardo:"Cristóbal Lozano, paradigma de la pintura limeña del siglo XVIII". Ponencia presentada en el III Congreso Internacional del Barroco Iberoamericano, realizado en Sevilla en octubre del 2001 y publicada en: Barroco Iberoamericano, territorio, arte, espacio y sociedad. Universidad Pablo de Olavide. Edit. Giralda S.L. Sevilla 2001. Tomo I, p.353.

Ravines, Roger: Los Museos del Perú. Breve historia y guía INC. Lima, 1989, p.30.

Se ha podido localizar en el Archivo Arzobispal de Lima: Doc. Expediente Matrimonial de Cristóbal Aguilar y Silbestra Morales. Serie: Pliegos Matrimoniales. Expediente: Diciembre: 1743:4.
} 
incluso realizó tasaciones como Lozano, no llegó a su nivel económico, ya que para el año de 1748 Lozano tenía casa en la cuadra que iba del colegio de Santo Tomás al monasterio de las Descalzas de San José, además de un solar adquirido en $1751^{7}$.

Al parecer el cuadro más antiguo de Cristóbal de Aguilar es el del virrey José Antonio de Mendoza Caañamo y Sotomayor, Marqués de Villagarcía, quien gobernó el Perú entre 1736 y 1745 . Lienzo firmado por partida doble, en los papeles que lleva en la mano donde se lee: "Ex.mo Sr. Está a los pies de V. Exc. Christoval de Aguilar" y en la cartela repintada donde ya se da cuenta del justificativo de su trascendencia histórica, de la fecha de muerte, y aunque sin fecha de ejecución, creemos que debió realizarlo hacia el final de su mandato, para la galería oficial de retratos de los virreyes. Al igual que él también Lozano pintó al gobernante, pero para la colección de Bravo de Lagunas, ya que figura uno en su Memoria de $1759^{\circ}$. En esta obra temprana de Aguilar es posible apreciar claramente las características propias de los retratos dieciochescos con figuras de cuerpo entero que tienen

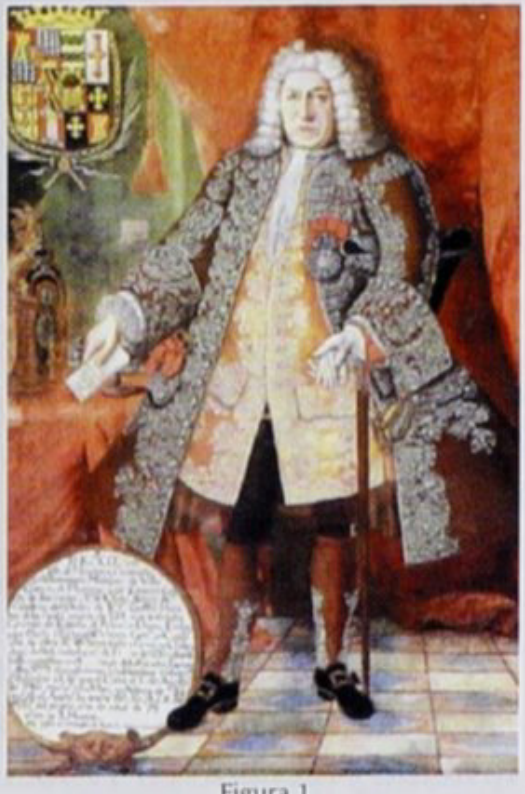

Figura 1 por marco un piso de baldosas en tonalidades pastel, un ampuloso paño rojo recogido como fondo, una mesa de gabinete, escudo nobiliario y cartela. Además ya se muestran en él las galas borbónicas en el traje colorido y ostentoso, con rameados de plata y medallas como la de la orden de Santiago. La peluca empolvada de la moda francesa enmarca un rostro que resalta el realismo y la búsqueda de la penetración sicológica, a través del dibujo severo y minucioso, lo que es muy propio de Aguilar (Fig. 1).

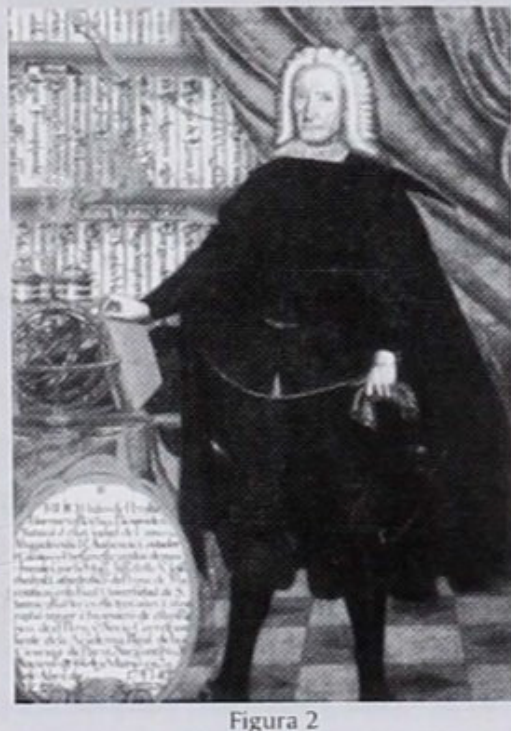

Figura 2

A diferencia del retrato oficial del virrey mencionado, Aguilar muestra, aparte de sus caracteres formales característicos, una mayor sobriedad en el color en el retrato póstumo de Pedro de Peralta Barnuevo y Rocha, rector de la Universidad de San Marcos entre 1715 y $1717^{9}$. Al parecer, al margen de la moda borbónica los catedráticos universitarios mantenían un severo traje negro, sin descuidar la calidad de la tela, como vemos en todos los retratos de esta época de la colección del Museo de Arte de la universidad decana de América. A ello se suma un fondo diferente que permite apreciar una amplia biblioteca y una mesa con libros o elementos que aluden a su especialidad en la cátedra, como es el caso de Peralta donde es posible leer en los lomos varios títulos de la variada y erudita producción literaria del políglota. El retrato es póstumo, de seguro tomado de una máscara de cera, porque él murió en 1743 y Aguilar firma el lienzo en 1751 (Fig.2). Existen en la

Estabridis, R.: op.cit. 2004, p.109.

Escribano Orencio de Ascarrunz. Prot. 83, 1765, fol. 477. AGN.

Stastny, Francisco: "La pintura limeña y los retratos de la Universidad de San Marcos". En Catálogo de exposición: Pintores y Catedráticos. UNMSM. Lima, 1975, p.28. 


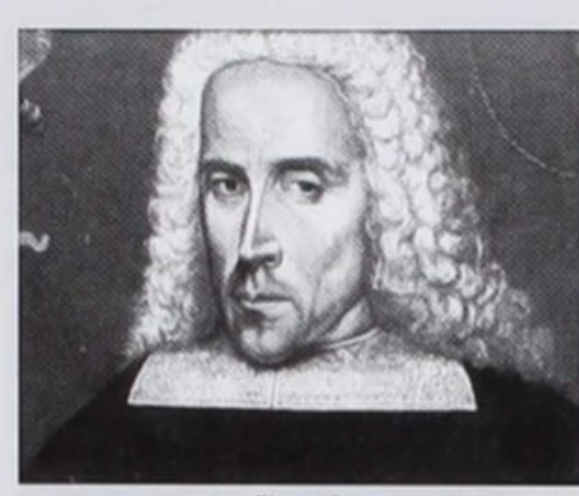

Figura 3

del limeño Diego Hurtado de Mendoza Iturrizaga ${ }^{10}$, quien fuera rector entre 1740 y 1742 , y el del panameño Antonio de la Cueva, catedrático de Prima de Teología Moral (Fig.3). En ambos, al igual que el de Peralta, el artista centra la atención en el rostro del personaje donde, lo que otros estudiosos anotan como dureza de pincel, nosotros vemos una gran capacidad para lograr fuerza expresiva. Pincel dibujístico que indudablemente difiere de la línea más pictórica del paradigmático Lozano.

Entre los retratos, un campo rico en este género en la pintura virreinal, que amerita un estudio más minucioso, es el de las religiosas. Hace poco salió a la luz, gracias a la restauración, un retrato de la abadesa doña Inés Muñoz de Rivera, fundadora del monasterio de la Concepción firmado por Mateo Pérez de Alesio, pintor italiano llegado a Lima en el siglo XVI, considerado el patriarca de la pintura colonial". Así como el citado existen muchos otros, y en el siglo que nos ocupa, Cristóbal de Aguilar dejó una excelente muestra salida de su pincel en el lienzo de la Venerable Madre Sor Francisca del Espíritu Santo Matoso ${ }^{12}$ firmado y fechado en 1756. La religiosa de velo negro, destacada en virtudes, según la leyenda que reza, ya no en la tipología de cartelas acostumbrada, sino en banda horizontal en la zona inferior del lienzo, fue pintada dos años después de su longeva vida, ya que murió de 92 años. En esta pintura consideramos que se pone de manifiesto, más que en cualquier otra, su gusto descriptivo, minucioso, centrado en los caracteres fisonómicos del personaje, sobre un fondo neutro. Aparte de ello destaca únicamente, el hábito de la orden, un misal en la mano y dos medallones devocionales de la Virgen con el Niño y la Inmaculada Concepción, sobre el pecho y el hombro, respectivamente, tratados en forma algo blanda (Fig.4).

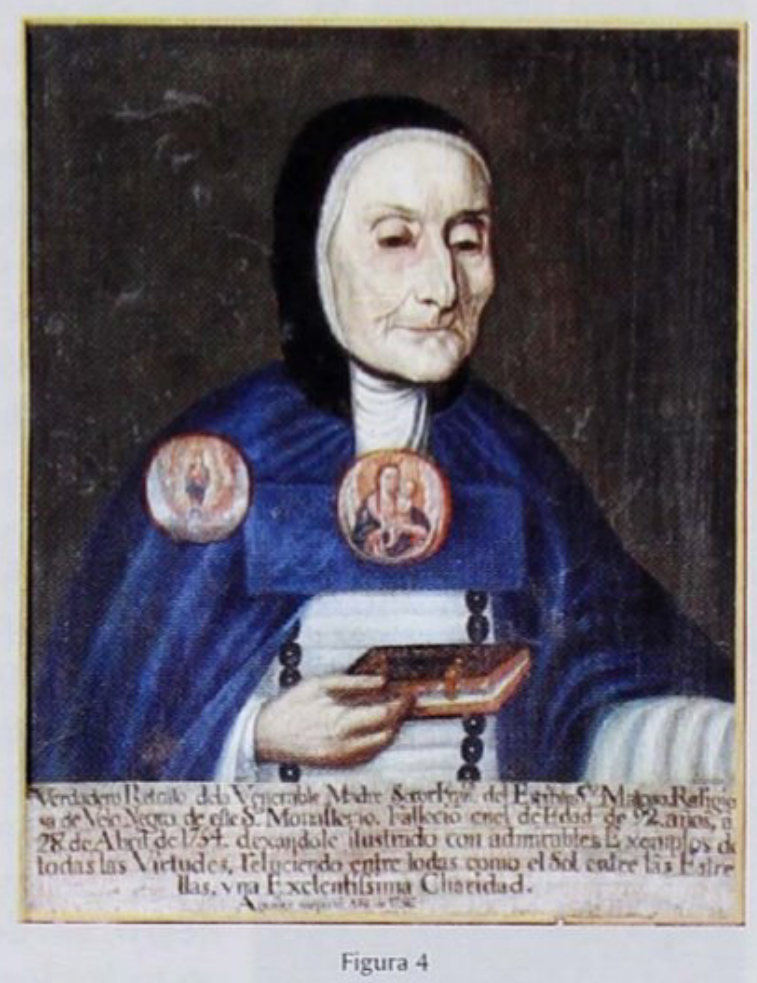

A los retratos de un virrey, un rector de San Marcos y una religiosa, sumamos uno firmado por Cristóbal de Aguilar del estamento femenino noble de la Lima dieciochesca, el de la primera marquesa de Torre Tagle, firma que sacáramos a la luz en reciente publicación ${ }^{13}$. La limeña, nacida en San Jerónimo de Sayán, doña Rosa Sánchez de Tagle e Hidalgo, casada en 1707 con el español don José Bernardo de Tagle Bracho y Pérez de la Riva, se convirtió en la primera marquesa en 1730 y cabeza

\footnotetext{
${ }^{10}$ Estabridis, Ricardo: "Recuperación del Patrimonio histórico-artístico de San Marcos. En Letras No 94 Revista de la facultad de Letras y Ciencias Humanas. UNMSM. Lima, 1997, p.31.

Diario El Comercio Lima,22 de agosto de 2004, p. C 1.

2Vargas Ugarte, Rubén: Ensayo de un Diccionario de artifices coloniales de la América Meridional. Lima, 1947. p. 288. El referido autor la cita con el apellido Motoso y dice que está pintada sobre tabla.

${ }^{3}$ Estabridis R.:op. cit. 2003, p. 163.
} 
de este destacado clan nobiliario criollo al quedar viuda en 1740 y fundar el mayorazgo familiar en 1756 . A nuestro parecer la cartela que figura a un costado es un repinte posterior; por ello, la firma aparece fuera de ella, en una zona ennegrecida y poco visible, por lo que había pasado desapercibida para otros estudiosos.

El retrato de la primera marquesa de Torre Tagle, debió ser realizado por Aguilar el año que la marquesa fundó el mayorazgo en 1756 (Fig.5), quizás conjuntamente con el retrato póstumo de su esposo, ya que reúnen ambos similares características. Es hasta el momento el único retrato femenino del pintor limeño que muestra en todo su esplendor, con el carácter descriptivo que caracteriza a nuestro artista, el gusto fastuoso de las limeñas por retratarse con ricas telas y ostentosas joyas, no inventadas por el

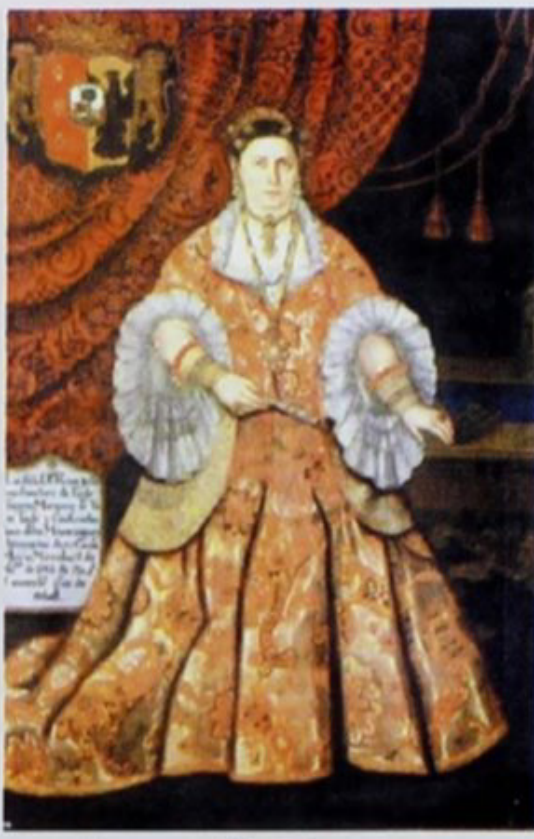

Figura 5 pintor ya que muchas son descritas en inventarios de la época.

Deseo sumar a estas líneas mi preocupación por el futuro de la colección de retratos de los marqueses de Torre Tagle que decoraron siempre el Palacio de su nombre y que han sido retirados de ella por sus actuales propietarios ${ }^{14}$.

Los cargos públicos en el siglo XVIII fueron ocupados cada vez en mayor medida por burgueses criollos y nobles de la Ciudad de los Reyes, incluso con la formación de los mayorazgos muchos de ellos se hicieron hereditarios. Un personaje destacado de esta época y que responde a estos casos fue inmortalizado por Aguilar, don José Rodríguez de Carassa, caballero de la Orden de Calatrava, Ensayador Mayor de las Provincias del Perú en las Cajas de Lima y de su Real Casa de Moneda, tal cómo se lee en la cartela que lo acompaña, la que remata con la firma del autor y la fecha 1797 (Fig.6). A la luz de nuevos documentos encontrados se puede determinar ahora que Aguilar murió el mismo mes de diciembre del año de 1769 en que hizo su testamento y fue enterrado según sus deseos en el convento de Santo Domingo ${ }^{15}$. Por ello, ya podemos llegar a la conclusión que el número 9 de la

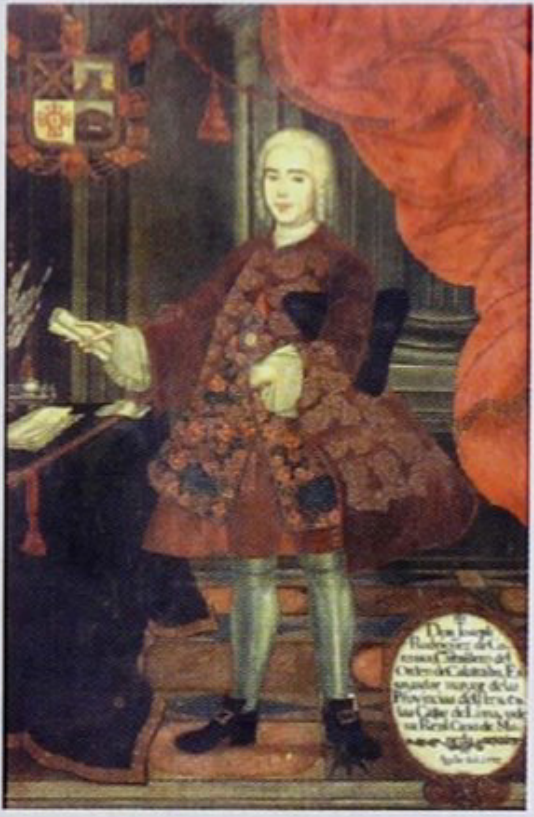

Figura 6 fecha 1797 que figura en el lienzo citado, realmente corresponde al número 5 y que quizás por su parecido en la grafia de la época, algún restaurador lo convirtió en un nueve y cambió la fecha real de 1757. Además según datos biográficos del representado, José Rodríguez de Carassa fue nombrado Ensayador Mayor de la Real

Chauny, Gilbert: "Los siete marqueses de Torre Tagle" en Diario El Comercio Lima, 30 de mayo del 2004 p. C 10.

Archivo Arzobispal de Lima. Doc. Defunción de Cristóbal de Aguilar. En Libro de Defunciones del Sagrario de 1767-1790. Tomo 9, folio 20 vta. Funeral del mes de Diciembre de 1769:20. Donde se lee: "en 28 entierro en Santo Domingo de don Xptobal de Aguilar". 


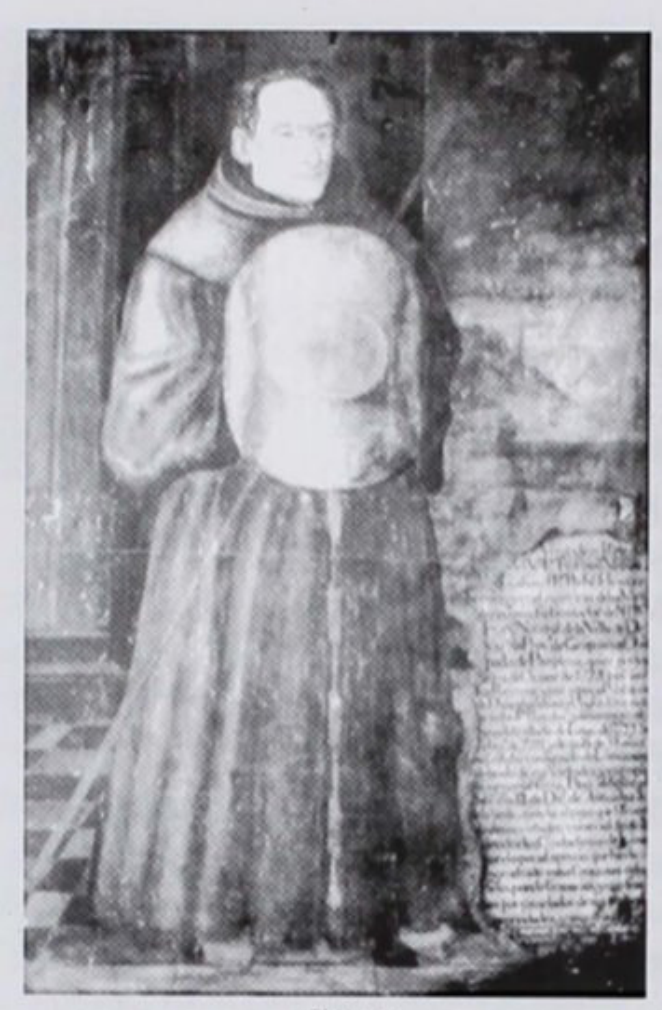

Figura 7

1748 e investido como Caballero de la Orden Militar de Calatrava el 13 de junio de 1753 . fechas próximas a la ejecución del referido retrato $^{16}$. Al margen de ello no cabe duda de la autoría; los caracteres formales así lo determinan. Rodríguez aparece con todas sus galas borbónicas a la moda de la época del rey Fernando VI, con chaleco floreado, casaca de terciopelo en tono siena y tricornio bajo el brazo izquierdo. El hallazgo de este documento de defunción de Aguilar también ha podido descartar definitivamente su participación en la serie de las pinturas de castas que envió el virrey Amat a España en 1770 .

La década de los años sesenta del siglo XVIII, última de su producción pictórica, se inicia con el retrato del franciscano descalzo Francisco Verástegui que se conserva en el Convento de Nuestra Señora de los Angeles del Rímac, firmado y fechado en 1767 (restaurado por el Banco de Crédito del Perú). Es una obra de discreta ejecución si la comparamos con las otras mencionadas anteriormente. El franciscano figura de pie sobre el característico piso de baldosas cubriéndose el pecho con un sombrero alón, mientras que el fondo se abre a paisaje a través de balcón con balaustrada. La amplia cartela hacia la derecha da cuenta de su vida y virtudes cristianas y de la autoría del lienzo (Fig.7). Existen en este convento otros retratos de similares características que podrían ser de su pincel, tal como el de Fray Manuel Hozes ${ }^{18}$. Dentro de este conjunto de retratos conventuales de religiosos destacados, hemos podido apreciar el del fraile agustino Francisco Javier Vásquez, firmado por Aguilar, sin fecha. El lienzo se encuentra en mal estado de conservación en el convento de San Agustín de Lima, pero se puede leer en la leyenda inferior que fue Procurador, Vicario General y nombrado Prior General el 9 de junio de 1753.

El catalán Manuel de Amat y Junyent gobierna el reino del Perú entre 1761 y 1776 por encargo del rey Carlos III. Su primer retrato, el oficial para la galería de virreyes, lo realizó de seguro Cristóbal Lozano, obra firmada pero sin fecha en el Museo de Magdalena, que sería tomada como modelo para los retratos realizados por otros pintores, entre ellos Aguilar y Pedro José Díaz ${ }^{19}$. Se tiene información de que Aguilar recibe 100 pesos por el retrato que hiciera del Virrey Manuel de Amat en 1768 para el Salón General de San Marcos, obra actualmente desaparecida ${ }^{20}$; asimismo, que al año

\footnotetext{
16 Tauro del Pino, Alberto: Enciclopedia llustrada del Perú. Edit. Peisa. Lima,2001. Tomo 14, p. 2280. "Wuffarden, Luis Eduardo: "Los lienzos del virrey Amat y la pintura limeña del siglo XVIII". En: Los cuadros del mestizaje del Virrey Amat. Edit. Museo de Arte. Lima, 2000, p. 57.

Saíz Díez, P. Fr. Félix: El Museo del Convento de los Descalzos. Lima, 2002, p. 117

"Varios Autores: Carlos III y la Ilustración. Ministerio de Cultura. Madrid, 1988. T. II, p. 736. También ver Cuyás, María Margarita: "Una pintura de procedencia colonial en la colección del MNAC: El retrato de Manuel D 'Amat I de Junyent, virrey del Perú del 1761 1I 1776". En Miscel-lánia en Homenatge a Joan Ainaud de Lasarte. Volum II. Barcelona, 1999, p. 143. De la misma autora ver: "El Virrey Amat". En Perú Indigena y Virreinal. SEACEX. Barcelona, 2004, p.266.

"Harth-terré, Emilio y Márquez Abanto, Alberto: "Pinturas y Pintores en Lima Virreinal". En: Revista del Archivo Nacional del Perú. Tomo XXVII. Entregas I y II. Lima, 1963, p. 65.
} 
siguiente pinta otro retrato de Amat, de carácter votivo, para el Monasterio de las Nazarenas (Fig.8). Este último de 1769, nos permite establecer la estrecha semejanza en cuanto a la composición, no así en el tratamiento de pincel, que en Lozano como sabemos es más pictórico, mientras que en Aguilar es más dibujístico.

El virrey Amat, al igual que su antecesor apreció a los pintores de la escuela limeña del siglo XVIII, ya que así como el virrey conde de Superunda, aparte de los retratos que dejó en Lima para inmortalizar su imagen, se llevó a España su retrato ecuestre firmado por Lozano, exhibido actualmente en el Museo de América de Madrid, igualmente Amat se llevó a Barcelona su retrato pintado por el limeño Pedro José Díaz, que ahora forma parte de la colección del Museo de Arte de Cataluña ${ }^{21}$.

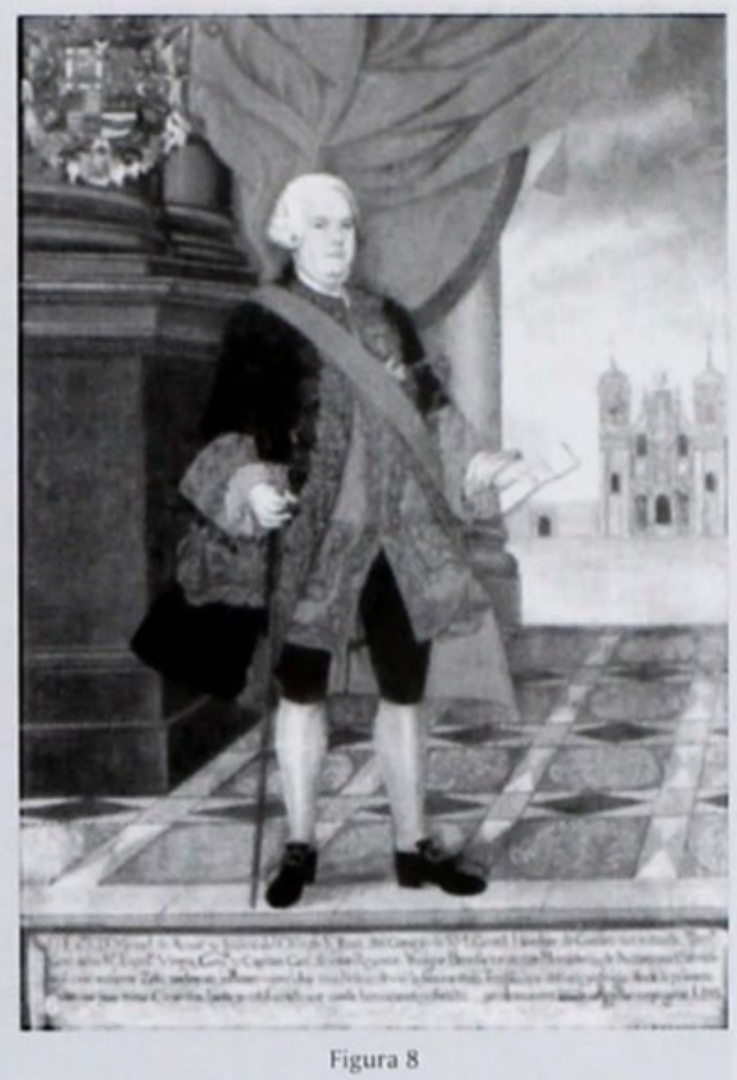

Los limeños del siglo XVIII fueron muy favorecidos en títulos nobiliarios por la dinastía borbónica entronizada en España desde este siglo, los que aumentaron este estamento con más de ochenta títulos, a diferencia de la dinastía anterior, los Habsburgo, que otorgaron muy pocos. Una de las familias de mayor prosapia, favorecidas en el siglo XVII con el marquesado de Santiago, fueron los Pérez Manrique de Lara, en la persona de don Dionisio, I Marqués de Santiago, en 1660 , gracias al rey Felipe IV ${ }^{22}$.

Actualmente en el Museo de la Nación, pero procedentes de la Quinta de Presa frustrado Museo del Virreinato desde hace muchos años-, se encuentran tres retratos de los marqueses de Santiago. Indudablemente los tres son pinturas de Cristóbal de Aguilar, dos de ellos aún conservan su firma y fecha, mientras que uno la ha perdido por lagunas en la cartela. La fecha de 1769 indica que fueron encargados por el último de ellos, don Dionisio Pérez Manrique de Lara, Roxas y Jarava, al figurar ya con el título como el III Marqués de Santiago. De seguro para inmortalizar a sus antepasados hizo el retrato de su padre y de su abuelo. Para el retrato póstumo de su abuelo, don Dionisio Pérez Manrique de Lara, I Marqués de Santiago, no cabe duda que el pintor se inspiró en el retrato de don Antonio Hermenegildo de Querejazu y Mollinedo, destacado patriarca de una de las familias más poderosas de Lima dieciochesca, lienzo sin firma que hemos atribuido a Aguilar $^{23}$. Es tan semejante en su composición y pose del personaje, que parece que el pintor sólo cambió los rasgos fisiognómicos de Querejazu, eliminó la biblioteca del fondo y algún otro pequeño elemento sobre la mesa adjunta; ambos visten traje negro con golilla y puños de encaje, guantes en la

\footnotetext{
"Cuyás, M: op.cit. 1999 y 2004.

"Lohmann Villena, Guillermo: "Los ministros de la Audiencia de Lima" (1700-1821). Escuela de Estudios Hispanoamericanos de Sevilla. Sevilla, 1974, p.185.

${ }^{n}$ Estabridis, R: op.cit. 2003, p.169.
} 

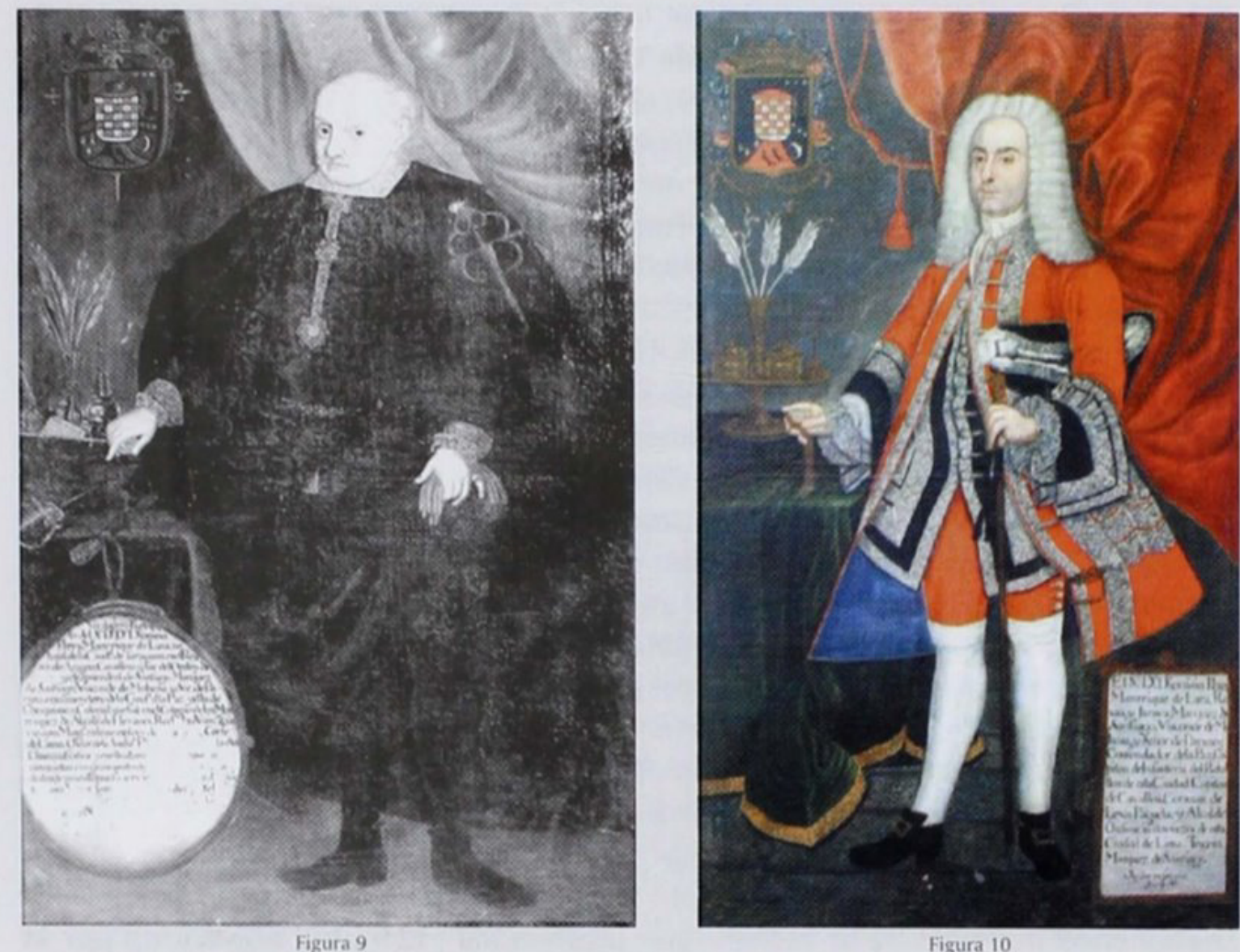

mano izquierda y reloj en la derecha, e igualmente la gran cruz de Santiago sobre la capa y medalla sobre el pecho. En general es la misma vestimenta sobria y algo arcaizante que hemos mencionado usaban los catedráticos de la Real y Pontificia Universidad de San Marcos (Fig.9y 10).

El retrato de don Carlos Francisco Pérez Manrique de Lara II Marqués de Santiago, a diferencia de su antecesor, viste galas típicamente borbónicas y responde claramente

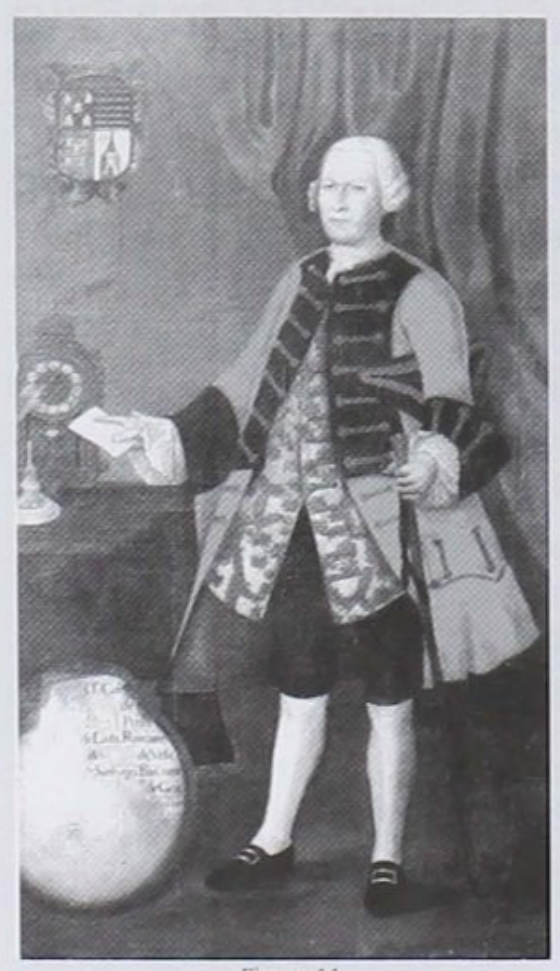
al modelo usado para los virreyes, desde la peluca empolvada cercana a la moda del rey ilustrado Carlos III, hasta los chalecos rameados en oro y casacas de rojo escarlata, bastón, tricornio bajo el brazo y carta en una mano (Fig.11).

Lastimosamente la cartela ha perdido gran parte del texto que da cuenta de la prosapia del personaje; sin embargo, la firma aparece fuera de ella, en la caja de un artístico reloj que figura sobre la mesa: "Aguilar fecit. A. 1769" (Fig.12).

El III Marqués de Santiago don Dionisio Pérez Manrique de Lara, Roxas y Jarava de seguro, como ya hemos mencionado, el que encargó los retratos, posa para Aguilar al igual que su padre con bastón y tricornio bajo el brazo, pero en lugar de la carta en la mano derecha lleva un reloj como el I Marqués. Aparte viste sus mejores galas en traje rojo, negro ys da cuenta de otros títulos nobiliarios y cargos 
plata que dan, conjuntamente con el cortinaje rojo granate y el mantel verde sobre la mesa, un toque de colorido vivaz y complementario, que contrasta un poco con su acostumbrado carácter dibujístico, algo severo, manifiesto aún en el rostro realista, enmarcado en gran peluca empolvada hasta los hombros. La cartela donde figura la firma de Aguilar y la fecha de 1769, además da cuenta de otros títulos nobiliarios y cargos públicos, como el que fue dos veces alcalde de la ciudad de Lima. En nuestra opinión es el mejor de los tres retratos de los marqueses de Santiago (Fig.13).

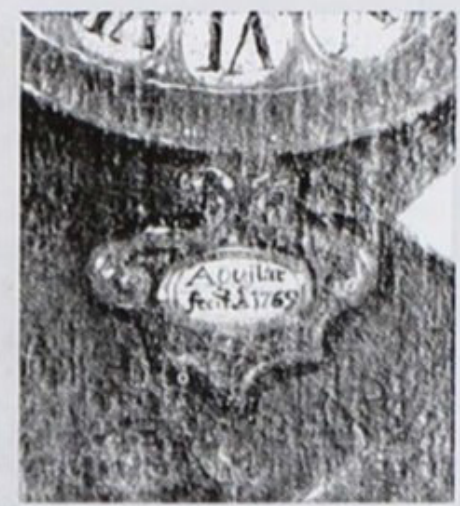

Figura 12

Según la partida de defunción Cristóbal de Aguilar fallece el 28 de diciembre de 1769, justo el año en que están fechadas las últimas obras estudiadas, pinturas de singular importancia como la de los marqueses de Santiago y la del virrey Amat, lo que indica un apogeo de su carrera que quedó frustrada por un accidente, mencionado mas no detallado en su testamento, que lo llevó a la muerte.

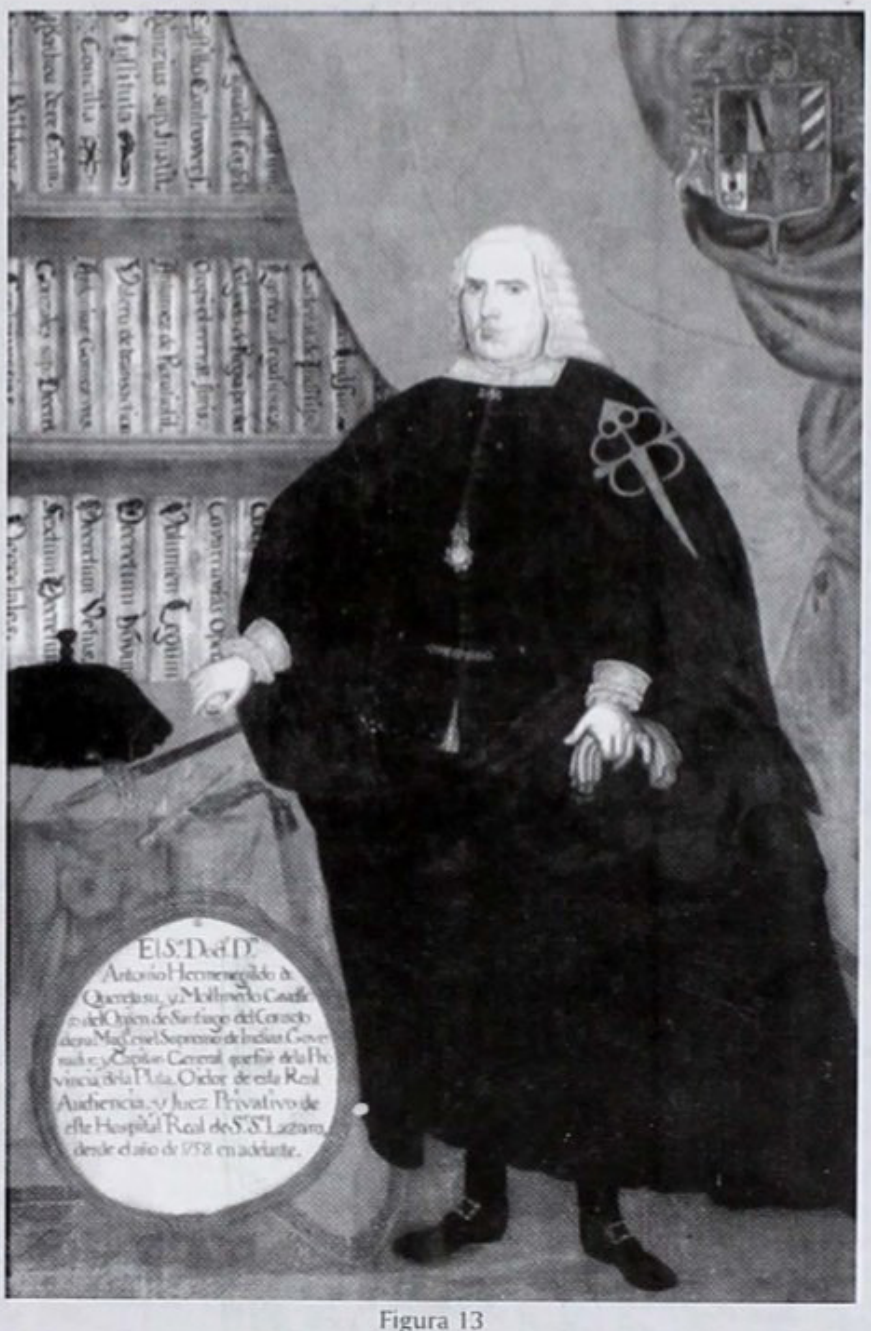


Testamento 1 Don Christo 2 Val Aguilar 3

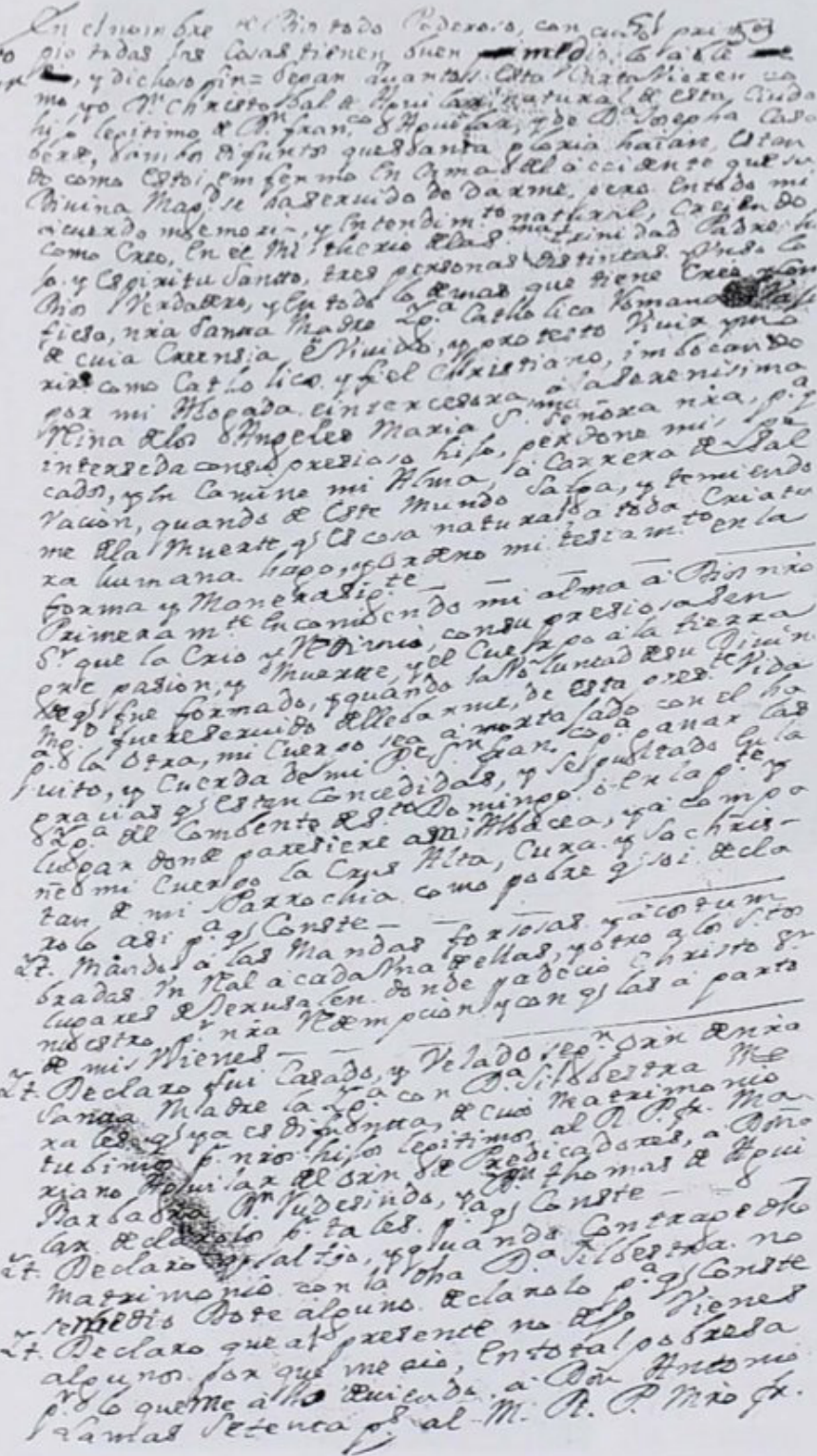

en el nombre de Dios todo Poderoso, con cuio princi pio todas las Cosas tienen buen medio loable y dichoso fin. Sepan quantos esta CartaVieren co mo yo Don Christobal de Aguilar natural de esta Ciudad hijo legitimo de Don Francisco Aguilar, y de Dona Josepha ' berde, ambos difuntos queS anta gloria haian, estan do como estoi emfermo en cama del accidente que su Divina Magestad se haservido de darme pero en todo mi acuerdo memoria, y entendimiento natural, creiendo como creo, en el Mistherio delaSantisima trinidad Padre hi he jo y espiritu Santto, tres personas distintas yVnso lo Dios Verdadero, y en todo lo demas que tiene cree y com fiesa, nuestra Santta Madre Yglesia Catholica romana Vajo de cuia Creensia eVivido, y protesto Vivir ymo rir como Catholico y fiel Christiano, imbocando por mi Abogada eintercesora a laserenisima reina delos Angeles Maria Santisima señora nuestra, para qaraa interseda consu presioso hijo, perdone mis pe cados, y en Camine mi Alma, a Carrera deSal vacion, quando de este Mundo Salga, y temiendo me dela Muerte que es cosa natural a toda Criatu ra humana hago, yordeno mi testamento en la forma y Manerasiguiente

Primeramente encomiendo mi alma a Dios nuestro Señor que la Crio y redimio, consu presiosaSan gre pasion, y Muertte, y el Cuerpo a la tierra de que fue formado, y quando laVoluntad desu Divina Magestad, fuereservido dellebarme, de esta presente Vida para la Otra, mi Cuerpo sea a mortajado con el ha vito, y Cuerda de mi Padre San francisco para ganar las gracias que estan concedidas, y sepultado en la Yglesia del Combento deSanto Domingo o en la parte y lugar donde paresiere ami Albacea, y a compa ñe mi Cuerpo la Crus Alta, Cura y Sachristan de mi Parrochia como pobre que soi decla ro lo asi para que Conste

37 Ytem Mando a las Mandas forsosas y acostum

38 bradas Vn real a cada Vna de ellas, y otro a los Santos 39 lugares dejerusalen donde padecio Christo Señor

40 nuestro por nuestra redempcion y con que las a parto 41 de mis Vienes

42 Ytem Declaro fui Casado, y Velado segun Orden de nuestra

43 Santta Madre la Yglesia con Doña Silbestra Mo

44 ra les que ya es difuntta de cuio Matrimo nio

45 tubimos por nuestros hijos legitimos al Reverendo Padre fra fr.fi 46 riano Aguilar del orden de Predicadores, a Doña

47 Barbara, Don rudesindo, y Don Thomas de Agui

48 Lar declarolos por tales para que Conste

49 Ytem Declaro que al tiempo, y quando Contrage dicho

50 Matrimonio con la dicha Doña Silbestra no

51 semedio Dote alguno declarolo para que Conste

52 Ytem Declaro que al presente no dejo Vienes

53 algunos por que me aio, en total pobresa

54 por lo que me allo deviendo a Don Antonio

55 Lamas Setenta pesos al Muy Reverendo Padre Maestro fray 


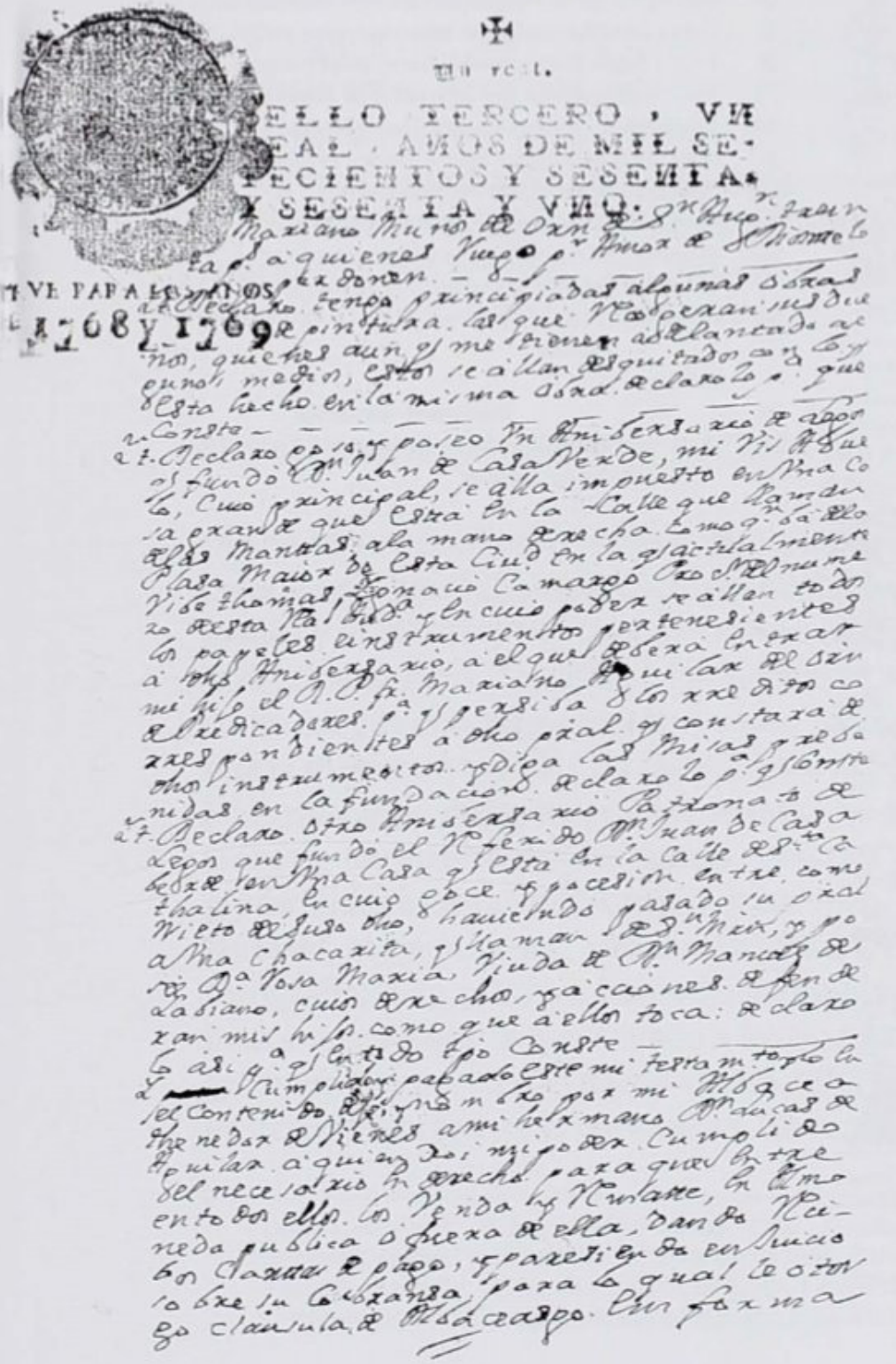

Mariano Muños del Orden deSan Agustin trein ta pesos a quienes ruego por Amor de Dios me lo perdonen

Ytem Declaro tengo principiadas algunas obras de pintura las que recogeran sus due ños, quienes aun que me tienen a delantado al gunos medios, estos se allan desquitados con lo que esta hecho en la misma obra declarolo para que Conste

10 Ytem Declaro goso y poseo Vn Anibersario de Legos

11 que fundo Don Juan de CasaVerde, mi Vis Abue

12 lo, Cuio principal, se alla impuesto en Vna ca

13 sa grande que estta en la Calle que llaman

14 delas Manttas ala mano derecha como quien ba dela

15 Plasa Maior de esta Ciudad en la que actualmente

16 Vibe Thomas Ygnacio Camargo Procurador del nume 17 ro deesta real Audiencia y en cuio poder se allan todos los papeles einstrumentos pertenesientes a dicho Anibersario, a el que debera entrar mi hijo el Reverendo Padre fray Mariano Aguilar del Orden de Predicadores para que persiba los rreditos co rrespondientes a dicho principal que constara de dichos instrumentos y diga las Misas prebe nidas en la fundacion declarolo para que Conste Ytem Declaro otro Anibersario Patronato de Legos que fundo el referido Don Juan de Casa berde en Vna Casa que esta en la Calle deSanta Ca thalina, en cuio goce y pocesion entre como Nieto delSuso dicho, haviendo pasado su principal aVna Chacarita, que llaman de San Martin, y po see Doña rosa Maria, Viuda de Don Manuel de Labiano, cuios de rechos, y a cciones defende ran mis hijos como que a ellos toca: declaro lo asi para que en todo tiempo Conste Y Cumplido y pagado este mi testamento ylo en el contenido dejo, ynombro por mi Albacea thenedor deVienes ami hermano Don Lucas de Aguilar a quien doi mi poder Cumplido el necesario en derecho para que entre en todos ellos los Venda y rematte, en Almo neda publica o fuera de ella, dando reci bos Carttas de pago, y paresiendo en Juicio so bre su Cobransa para lo qual le otor 44 go clausula de Albaceasgo em forma 


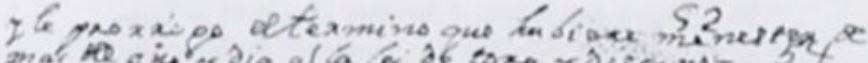

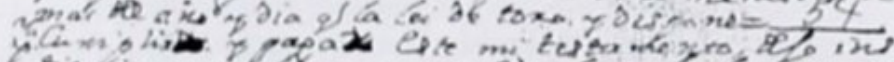

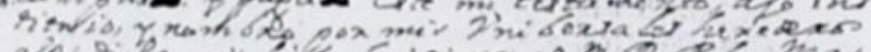

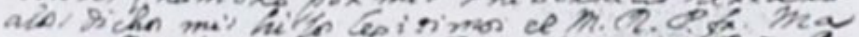

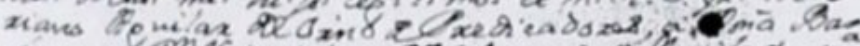

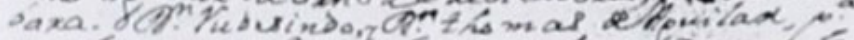

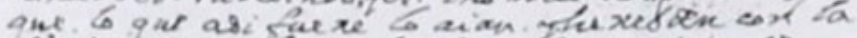

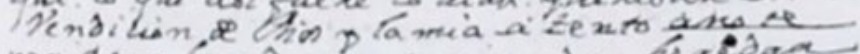

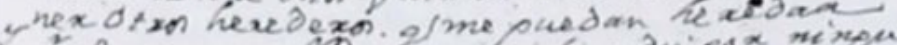

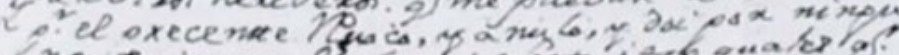

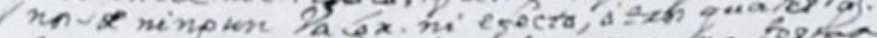

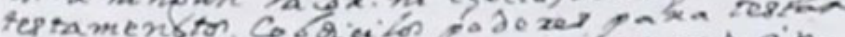

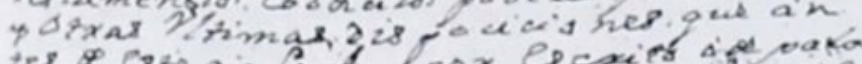

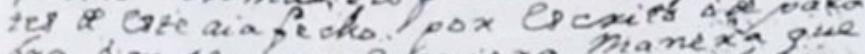

bxa. bre spá qual quiexa manexá gain

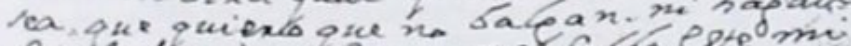

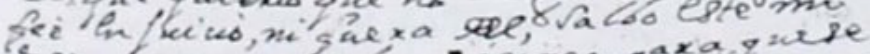

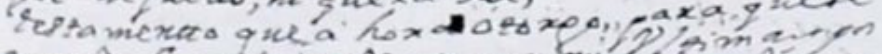

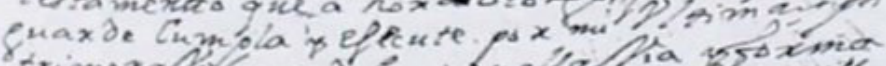

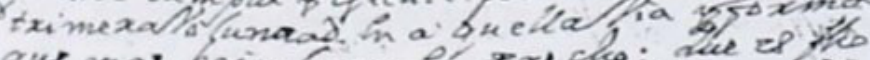

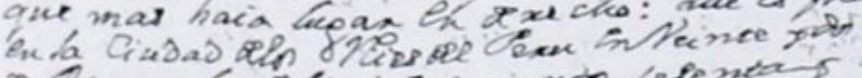

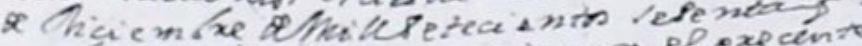

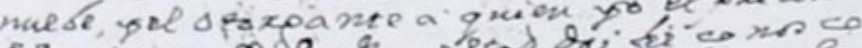

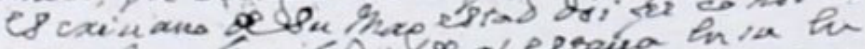

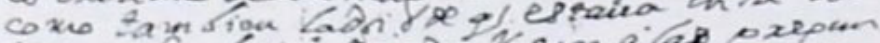

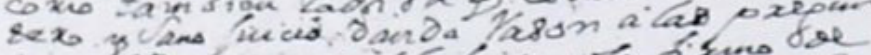

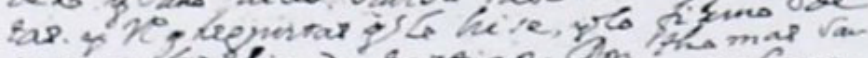

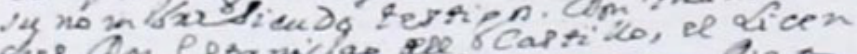

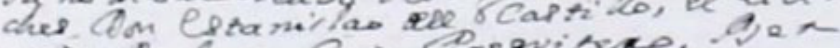

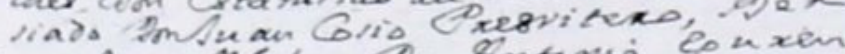

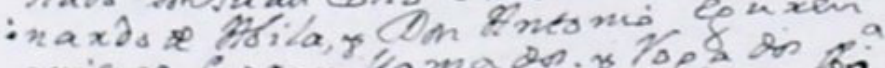

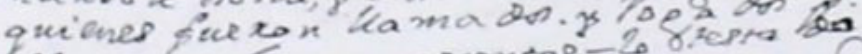

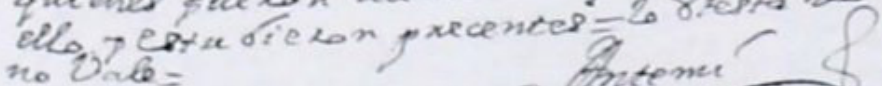

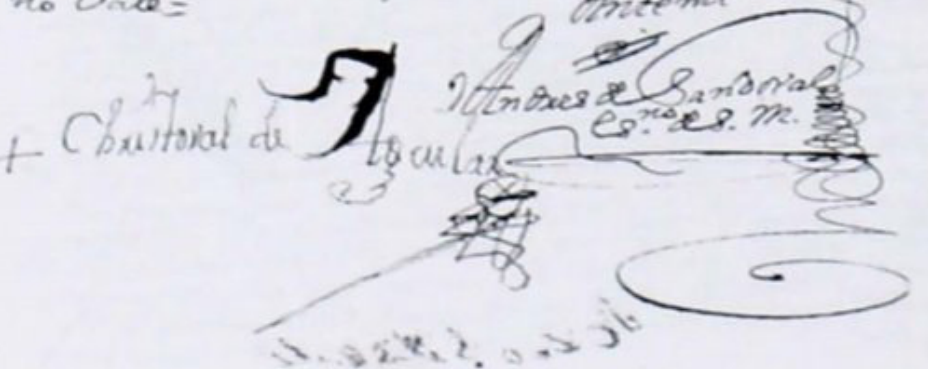

y le prorrogo eltermino que hubiere menester de mas del ano y dia que la lei de toro y dispone. Ypara Cumplir y pagar este mi testamento, dejo ins tituio, y nombro por mis Vnibersales herederos alos dichos mis hijos legitimos el Muy Reverendo Padre frare f riano Aguilar del Orden de Predicadores, a Dona Bar bara. Don rudesindo, y Don Thomas de Aguilar, para que lo que asi fuere lo aian yhereden con la rendicion de Dios y la mia atento ano te ner Otros herederos que me puedan heredar $\mathrm{Y}$ por el precentte revoco, $y$ anulo, $y$ doi por ningu nos de ningun Valor ni efecto, otros quales quier testamentos Cobdicilos poderes para testar y Otras Vltimas dispociciones que an tes de este aia fecho por escrito o de pala bra o en otra qual quiera manera que sea, que quiero que no balgan ni hagan fee en Juicio, ni fuera deel, salbo este mi testamentto que a hora otorgo, para quese guarde Cumpla y ejecute por mi Vitimay pos trimeraVolunttad en a quellaVia yforma que mas haia lugar en derecho: que es fecho en la Ciudad delos reies del Peru enVeinte ydos de Diciembre deMillSetecientos sesentay nuebe, y el otorgante a quien yo el precente escrivano deSu Magestad doi fee conosco como tambien ladoi de que estava en su en tero y Sano Juicio dando rason a las pregun tas y repreguntas que le hise, y lo firmo de su nombreSiendo testigos Don Thomas San ches Don estanislao deel Castillo, el Licen siado Donjuan Cosio Presvitero, Ber nardo de Abila, y Don Antonio eguren quienes fueron llamados y rogados para ello y estubieron precentes. lo testa do no Vale.

Firmas: Antemi 